\title{
Epidemiological Study of Animal Bites and Rabies in Bandar Astara City in 2017
}

\section{Dehgorji NR, Adham D, Abazari M and Mordi Asl E* \\ Department of Public Health, Ardabil University of Medical Sciences, Iran}

*Corresponding author: Eslam Moradi Asl, Department of Public Health, School of Public Health, Ardabil University of Medical Sciences, Ardabil, Iran, Tel: 00989050262483; Email: moradiasl83@yahoo.com

\section{Research Article}

Volume 2 Issue 2

Received Date: March 16, 2019

Published Date: March 28, 2019

DOI: $10.23880 /$ izab-16000142

\section{Abstract}

Introduction: Rabies is a viral disease that virus is removing from body during an animal's bite and can cause death. The aim of this study was to determine of the epidemiologic cases of animal bite and rabies in Northern of Iran.

Method: This cross-sectional descriptive study was conducted on 150 cases in Bandar Astara city in 2017. Data were collected using a researcher-made checklist. For analyze the data we used SPSS 22.

Results: In this study, $78 \%$ of cases were males and $22 \%$ of females. The mean age was $34.25 \pm 19.41$. Most cases of animal bites occurred at age 50 and older. 49.3\% of cases were in the urban and 50.7\% in the rural area. Most of animal bites happened by the dog. $97.3 \%$ of animals were domesticated. The majority bites were happened in leg $83(55.3 \%)$.

Conclusion: The results of the study showed that animal bite is still one of the public health problems in the Astara city. Therefore, the necessary measures to prevent and minimize animal bites are necessary.

Keywords: Animal Bites; Astara; Epidemiological Studies

\section{Introduction}

Animal bite is one of the important threats to human health. Rabies is a viral disease that virus is removing from body during an animal's bite. Rabies is one of the most important causes of mortality, especially in developing countries [1-3].

The incidence of animal bites in the United States is estimated at 200 per 100000 persons per year [4]. In each of two areas in Italy (Bologna and South Tyrol), the incidence of bites was separately determined to be 50-60 per 100000 persons per year [5].

In Iran, in 2013, there were about 150,000 animal bites and 4 cases of rabies. According to the state of animal bites in 2012, the highest incidence of rabies is in the provinces of Golestan and Ardebil (393-503 per 100,000 people). Dog biting in several developing countries is epidemic and more than $90 \%$ of all bites are included. Increasing the number of stray dogs and animal bites cases indicates the importance of disease and the need for action [6-9]. 


\section{International Journal of Zoology and Animal Biology}

The city of Bandar Astara, with an area of 344 square kilometers, is located in the northwest of Guilan province. In the west of this city located the mountains covering by Talesh, et al. forest and on the east coast of the Caspian Sea. In the north of the city is the Astara River or Astara Tea, which is the border line between Iran and the Republic of Azerbaijan and divides Astara into two parts of the Astara region of Azerbaijan and Iran. The city has a border division, three rural districts (Lundwill, Veremoni and Heiran) and 64 villages. The climate of Astara is moderate and humid, with spring and autumn rainy between 1200 and $1400 \mathrm{~mm}$, and a moderate temperate with fertile and sedimentary soils for agriculture, forest cover is one of the major characteristics of the city [10].

Since, after clinical symptoms in humans and animals, the disease cannot usually be treated and cause death [11-15]; Therefore, the first step in controlling the disease is epidemiological studies $[1,13]$. The aim of this study was to determine the epidemiologic cases of animal bite and rabies in Bandar Astara.

\section{Method}

This descriptive cross-sectional study was performed on the individuals of all animal bites recorded in the Healthcare facility Astara in 2017. The total number of referrals was 150 . To collect this information, a researcher-made checklist that was approved by the experts was used. For analyze the data we used SPSS 22.

\section{Results}

In this study, $117(78 \%)$ males and 33 (22\%) females of animal bites were reported. The mean age of the participants was $34.25 \pm 19.41$, and the most cases of animal bites were observed in the age range of 50 years and older (26\%). The age of the least injured was 2 years old and the oldest was 79 years old. Of the total cases, 74 $(49.3 \%)$ were resident in the city and $76(50.7 \%)$ were in the village. Among the employed, people with free occupation had the most cases of animal bites, then, respectively, students with 29 cases and housewives with 21 cases had the most number of animal bites (Table 1).

\begin{tabular}{|c|c|c|c|}
\hline \multicolumn{2}{|c|}{ Demographic Features } & No. & \% \\
\hline \multirow{3}{*}{ Sex } & Male & 177 & 78 \\
\cline { 2 - 4 } & Female & 33 & 22 \\
\hline \multirow{4}{*}{ Age (years) } & $1-9$ & 15 & 10 \\
\cline { 2 - 4 } & $10-19$ & 25 & 16 \\
\cline { 2 - 4 } & $20-29$ & 25 & 16 \\
\cline { 2 - 4 } & $30-39$ & 31 & 22 \\
\cline { 2 - 4 } & $40-49$ & 15 & 10 \\
\hline \multirow{4}{*}{ Location } & 50 and above & 39 & 26 \\
\hline \multirow{6}{*}{ Job } & Urban & 74 & 49.3 \\
\cline { 2 - 4 } & Rural & 76 & 50.7 \\
\cline { 2 - 4 } & Cattleman & 5 & 3.3 \\
\cline { 2 - 4 } & Farmer & 4 & 2.7 \\
\cline { 2 - 4 } & Employee & 4 & 2.7 \\
\cline { 2 - 4 } & Free & 40 & 26.7 \\
\cline { 2 - 4 } & Worker & 9 & 6 \\
\cline { 2 - 4 } & Housewife & 21 & 14 \\
\cline { 2 - 4 } & Student & 29 & 19.3 \\
\hline
\end{tabular}

Table 1: The results of animal bites and some demographic variables.

Out of all cases of animal bites, 5 types of invasive animals were identified, most of them happened by the dog. Out of all invasive animals, 146 (97.3\%) were domesticated and $4(2.7 \%)$ were wild. We also investigated the invasive animals for fate (under observation, stray, fled and killed), that animals under observation were the highest cases 116 (77.3\%) (Table 2). 


\section{International Journal of Zoology and Animal Biology}

\begin{tabular}{|c|c|c|c|c|}
\hline Feature & Animal Specifications & Male & Female & Total \\
\hline \multirow{4}{*}{ Invasive Animal Type } & Dog & 105 & 22 & 127 \\
\cline { 2 - 5 } & Cat & 9 & 9 & 18 \\
\cline { 2 - 5 } & Jackal & 1 & 0 & 1 \\
\cline { 2 - 5 } & Raccoon & 2 & 1 & 3 \\
\cline { 2 - 5 } & Rabbit & 114 & 32 & 146 \\
\hline \multirow{3}{*}{ Animal Ownership Status } & Domesticated & 92 & 1 & 4 \\
\cline { 2 - 5 } & Wild & 15 & 5 & 20 \\
\hline \multirow{3}{*}{ The Destiny of the Invasive Animal } & Under Observation & 8 & 3 & 11 \\
\cline { 2 - 5 } & Stray & 2 & 1 & 3 \\
\cline { 2 - 5 } & Fled & Killed & & 1 \\
\hline
\end{tabular}

Table 2: Type of animal and relationship to frequency of animal bites.

The animal's bite site was divided into 5 sections. It was found that majority had animal bites on leg 83(55.3\%). Results showed that 116 animal bites needed partial treatment ( 3 times the vaccine) and 34 patients needed complete treatment (5 times the vaccine). Also, $124(82.7 \%)$ patients did not need to receive anti-rabies serum and their injuries improved with vaccine, and 26 $(17.3 \%)$ needed anti-rabies with vaccine (Table 3).

\begin{tabular}{|c|c|c|c|}
\hline Site Bite & Male & Female & Total \\
\hline Leg & 68 & 15 & 83 \\
\hline Hand & 38 & 13 & 51 \\
\hline Body & 8 & 2 & 10 \\
\hline Face & 2 & 3 & 5 \\
\hline Neck & 1 & 0 & 1 \\
\hline
\end{tabular}

Table 3: The location of injury in human's body.

\section{Discussion}

In this study, the number of animal bites in males $(78 \%)$ was higher than females (22\%); it was similar to the studies by BabaeyanMoghadam and colleagues $(68.7 \%$ males, 31.3\% females), Nikbakht, et al. [16] (598 miles from 722 case), and Dhand, et al. (62\% males, 38\% females)[14-17].

The present study showed that 74 cases $(49.3 \%)$ were resident in the city and 76 (50.7\%) were resident in the village. In study of Sarbishgi, et al. [15,18], $81.7 \%$ were from the village: In the study of Nikbakht, et al. [16] of the 722 cases of animal bites, 528 were rural.

In the analysis of the results of this variable can be stated that unlike other studies, there is not much difference between urban and rural animal bites. It may be due to the lack of organizing animals in urban areas by the municipality.In our research, people with free occupation $(25.3 \%)$ had the most cases of animal bites, then students (19.3\%) and housewives (14\%) had the most cases of animal bites, respectively. But in the study of Bahoner, et al.[16,19], 34.4\% of the subjects were students, and after that, farmers and cattlemen $(20.9 \%)$ were the priorities. The study of Charkzai and colleagues [20] in AqQala also showed that $28.9 \%$ of cases of animal bites occurred in students.Out of all cases of animal bites, 5 types of invasive animals were identified, most of them happened by the dog (84\%).In studies conducted by SarbisheghMoghadam and colleagues [18], Barzkar and colleagues [21], Sangeetha, et al. [22], Navneet K and colleagues [17], 83.5\%, 86.7\%, 94.49\%, 63.77\%, 95.5\% of the animal was biting by the dog, respectively. The results of this study showed that 97.3 percent of all animal bites were domesticated animals and 2.7 percent by wild animals:Which is consistent with the results of SarbishghiMoghadam and colleagues [18] (84.5\%), BabaeyanMoghadam and colleagues [15] (95.2\%), and Sangeetha, et al. [22] (59.4\%). The results of the study by Brazkar and colleagues [21] also showed that the most cases of animal bites have occurred by domestic animals. However, the study by Navneet $\mathrm{K}$ and colleagues [17], contrary to the results of previous studies, showed that $71 \%$ of cases had occurred with stray dogs. This suggests that the presence of a high density of dogs on the street (commonly seen in developing countries, including Bhutan) is a risk factor for increased reports of dog bites incidents in Bhutan.In terms of bite site, it was found that majority had animal bites on leg 83(55.3\%) [23-25]. In the study, Barzkar and colleagues [21] had $60.95 \%$ of the bites on the lower extremities, and in the study of Sangeetha, et al. [22], 42 cases $(60.87 \%)$ were on leg. Navneet K and colleagues [17] showed that most (90\%) dog bites were inflicted on the extremities with $73 \%$ on the legs and $18 \%$ on the hand/arms. 


\section{International Journal of Zoology and Animal Biology}

Results showed that 116 animal bites needed partial treatment ( 3 times the vaccine) and 34 patients needed complete treatment (5 times the vaccine). Also, 124 $(82.7 \%)$ patients did not need to receive anti-rabies serum and their injuries improved with vaccine.The study by Barzkar and colleagues [21] found that $3.2 \%$ of the individuals received vaccine once, $14.2 \%$ twice, $81.1 \%$ of them three times and $1.6 \%$ received more than 4 times. Amiri, et al. [23] reported $100 \%$ complete vaccination, of which 570 received only vaccine and 18 received Gamma globulin with vaccine. Findings from SabouriGhannad and colleagues [24] also showed that 3596 cases $(81.3 \%)$ had partial vaccine and 824 cases $(18.7 \%)$ had received complete vaccine.

\section{Conclusion}

Given that most cases of animal bites have been inflicted by the dog, the organs concerned should take necessary measures to organize these animals. Also give dog owners the necessary training. Considering that in this study in the urban areas there was a relatively high prevalence of animal bites, we should prevent the spillage of waste products in front of homes and pedestrians and maintain environmental health.

\section{Acknowledgments}

In the end, we would like to thank all the staff at Astara Health Centers who helped us with this study.

\section{References}

1. Dadypour M, Salahi R, Ghezelsofla F (2009)Epidemiological survey of animal bites in Kalaleh district, North of Iran (2003-05). Journal of Gorgan University of Medical Sciences 11(1).

2. Madhusudana S (2005) Rabies: an ancient disease that still prevails. Indian J Med Res 122(1): 4-6.

3. Thiptara A, Atwill ER, Kongkaew W, Chomel BB (2011)Epidemiologic trends of rabies in domestic animals in southern Thailand, 1994-2008. Am J Trop Med Hyg 85(1): 138-145.

4. (2008) C N. Animal and human bites. J Emerg Nurse 16: 26-29.

5. Morosetti G, Toson M, Piffer (2013) Lesions caused by animals in the Autonomous Province of South Tyrol in 2010: fact-finding for prevention. VetItal 49(1): 3750.

Mordi Asl E, et al. Epidemiological Study of Animal Bites and Rabies in Bandar Astara City in 2017. Int J Zoo Animal Biol 2019, 2(2): 000142.
6. Tabatabaie SM, Zhraie M, Ahmadnia H, Ghotbi M, Rahimi F (1391) Principles of Disease Prevention and Surveillnce.

7. Gibbons RV (2002) Cryptogenic rabies, bats, and the question of aerosol transmission. Annals of Emergency Medicine 39(5): 528-536.

8. Fayaz A, Simani S, Janani A, Farahtaj F, Esfandyari B, et al. (2010) Epidemiological survey of rabies in Iran north provinces in ten years (1998-2007). Iranian Journal of Infectious Diseases and Tropical Medicine 14(47): 1-5.

9. Behnampour N, Charkazi A, Fathi M, Esmaeili A, Shahnazi H, et al. (2013) Epidemiology of Animal Bite in AqQala Citynorthen of Iran.J Educ Health Promot 2: 13.

10. Ghafouri M,Yaghubi M, Nasiri ZGD, Seyed SS (2015) An epidemiologic study of animal bites in bojnurd city 2005-2011. Journal of North Khorasan University of Medical Sciences 7(1): 123-131.

11. Sharifeian J, Simani S, Shirzadi M, Fayaz A, Hooshmand B (2003) Guideline state rabies disease. Tehran: Seda Publication.

12. Moghaddam MB, Nazari SSH, khodakarim S (2015) Epidemiological study of animal bites and its related damages in Qouchan city in 2013. Journal of Safety Promotion and Injury Prevention 3(1): 14-19.

13. Nikbakht $H$, Heydari $H$, Ghafarifam $S$, MalakzadehKebria R, MostaffaMirzad S, et al. (2015) Epidemiological Patterns of Animal Bite Injuries in Victims under 18 Year Old in Babol, Iran (2010-14). J BabolUniv Med Sci 17(11): 67-73.

14. Dhand NK, Gyeltshen T, Firestone S, Zangmo C, Dema C, et al. (2011) Dog bites in humans and estimating human rabies mortality in rabies endemic areas of Bhutan. PloS 5(11): e1391.

15. SarbishgiMoghadam M, Mehranpour R, Abdollahzadeh R (2016) Epidemiologic Study of Animal Bites in Sarbisheh County 2011-16. Beyhagh 21(4): 38-45.

16. Bahonar A, Bokaie S, Khodaveirdi K, Nikbakht Boroujeni G, Rad M (2008) A Study of Rabies and the Frequency of Animal Bites in the Province of Ilam, 1994-2004. Iranian Journal of Epidemiology 4(1): 4751. 


\section{International Journal of Zoology and Animal Biology}

17. Charkazi A, Behnampour N, Fathi M, Esmaeili A, Shahnazi H, et al. (2013) Epidemiology of animal bite in AqQala city, northen of Iran. J Educ Health Promot 2: 13 .

18. Dalla Villa P, Kahn S, Stuardo L, Iannetti L, Di Nardo A, et al. (2010) Free-roaming dog control among OIEmember countries. Prev Vet Med 97(1): 58-63.

19. Khokhar A, Meena G, Mehra M (2003) Profile of dog bite cases attending MCD dispensary at Alipur, Delhi. Indian J Commun Med 28(4): 157-159.

20. Pancharoen C, Thisyakorn U, Lawtongkum W, Wilde $\mathrm{H}$ (2001) Rabies exposures in Thai children. Wilderness \& environmental medicine 12(4): 239243.
21. Barzkar H, Shamshirgaran SM, Ghaffari Fam S, Ghasem Zadeh P, Bayat Maku Z (2016) Epidemiological patterns of animal bite patients under 10 year old, in Maku county, West Azerbaijan. Medical Journal of Tabriz University of Medical Sciences and Health Services 37(6): 6-11.

22. Sangeetha S, Sujatha K, William RF (2017) An epidemiological study of animal bites among rural population in Tamil Nadu, India. Int J Commu MedPub Health 3(6): 1413-1418.

23. Amiri M, Khosravi A (2009) Epidemiological study of animal bites in Shahrood.

24. Ghannad MS, Roshanaei G, Rostampour F, Fallahi A (2012)An epidemiologic study of animal bites in Ilam Province, Iran. Arch Iran Med 15(6): 356-360. 